\title{
Two Measures of Core Inflation: A Comparison
}

\author{
Jim Dolmas and Evan F. Koenig
}

Trimmed-mean personal consumption expenditure (PCE) inflation does not clearly dominate PCE inflation excluding food and energy in real-time forecasting of headline PCE inflation. However, trimmed-mean inflation is the superior communications and policy tool because it has been a lessbiased real-time estimator of headline inflation and because it more successfully filters out headline inflation's transitory variation, leaving only cyclical and trend components. (JEL E31, E37, E52)

Federal Reserve Bank of St. Louis Review, Fourth Quarter 2019, 101(4), pp. 245-58.

https://doi.org/10.20955/r.101.245-58

\section{INTRODUCTION}

Most central banks describe their price stability goals in terms of the behavior of an allitems price index. For example, each January since 2012, the U.S. Federal Reserve's Federal Open Market Committee (FOMC) has reaffirmed its judgment that "inflation at the rate of 2 percent, as measured by the annual change in the price index for personal consumption expenditures [PCE], is most consistent over the longer run with the Federal Reserve's statutory mandate." Nevertheless, "core" inflation measures often play a prominent role in the forecasting frameworks used by policymakers, as well as in their narrative accounts of realized inflation outcomes. The economic projections published four times per year by the FOMC, for example, include policymakers' projections both for all-items PCE inflation and for PCE inflation excluding food and energy (ex-food-and-energy PCE inflation). Monetary policy statements by the Reserve Banks of New Zealand and Australia often make explicit reference to measures of core inflation, and the Bank of Canada monitors core inflation measures as an "operational guide to help the Bank achieve the total CPI [consumer price index] target" (Bank of Canada, 2018).

Broadly, the motivation for monitoring a core inflation measure is that headline inflation is subject to large transitory shocks unrelated to changes in cyclical inflation pressures or the

Jim Dolmas is a senior economist and policy advisor and Evan F. Koenig is a senior vice president and principal policy advisor at the Federal Reserve Bank of Dallas. This article benefitted from research assistance provided by Emil Mihaylov and from suggestions offered by the Review editor-in-chief.

(C) 2019, Federal Reserve Bank of St. Louis. The views expressed in this article are those of the author(s) and do not necessarily reflect the views of the Federal Reserve System, the Board of Governors, or the regional Federal Reserve Banks. Articles may be reprinted, reproduced, published, distributed, displayed, and transmitted in their entirety if copyright notice, author name(s), and full citation are included. Abstracts, synopses, and other derivative works may be made only with prior written permission of the Federal Reserve Bank of St. Louis. 


\section{Dolmas and Koenig}

public's confidence in the central bank's commitment to long-run price stability. This transitory variation potentially complicates both inflation forecasting and policymaking.

As regards forecasting, stripping statistical noise from the left-hand side of an equation prior to its estimation yields more-precise coefficient estimates, increasing the chances that the fitted equation will produce superior forecasts. In the current context, there is an advantage to forecasting headline inflation using an equation estimated with core inflation on its left-hand side, to the extent that the difference between headline and core inflation can't be forecasted.

As regards policymaking, there are both theoretical and practical reasons for thinking that central banks should react more strongly to that portion of headline inflation that is core inflation than to that portion of headline inflation that is not core inflation. According to theory, policy should stabilize "sticky" prices. 1 To the extent that deviations of headline inflation from core are driven by volatile, flexible-price components of the headline index, therefore, those deviations should receive reduced weight in the policy reaction function. Practically, monetary policy affects inflation with a substantial lag, so a strong policy response to transitory inflation movements risks having policy provide stimulus when underlying cyclical inflation pressures are waxing or having policy apply restraint when underlying cyclical pressures are waning.

Policymakers also sometimes draw inferences about slack from the behavior of inflation. If inflation remains low or fails to increase despite historically low unemployment, it is tempting to infer that the natural rate of unemployment must have declined. Such inferences are reliable, however, only to the extent that there is a tight empirical link between inflation and labor-market slack. As discussed above, in a forecasting context, one will more accurately identify any such link if one strips idiosyncratic noise from headline inflation before estimation.

In this article, we compare two alternative measures of core PCE inflation: ex-food-andenergy PCE inflation and trimmed-mean PCE inflation. $\underline{3}$ Given the trimmed mean's relatively late introduction (in 2005), it is only recently that we have a sufficiently long history to perform a real-time comparison between the two core measures.

We start with a brief history of core inflation. Then, we examine whether either ex-foodand-energy PCE inflation or trimmed-mean PCE inflation is useful in real-time forecasting of headline inflation and whether either core measure has a reliably tight empirical link to slack. We discover that both trimmed-mean and ex-food-and-energy PCE inflation are useful in real-time forecasting of headline PCE inflation and that neither core measure has a strong, consistent forecasting advantage over the other. However, the trimmed-mean measure has exhibited less real-time bias than the ex-food-and-energy measure and is more tightly linked to labor-market slack than is either headline inflation or the conventional core measure. For those reasons, trimmed-mean should arguably receive greater weight than headline and ex-foodand-energy PCE inflation in policy discussion and Federal Reserve communications.

\section{A SHORT HISTORY OF CORE INFLATION}

The earliest core inflation measures were exclusion based-that is, of the form "inflation excluding [items X, Y, and Z]," as in the U.S. CPI excluding food and energy or ex-food-and- 
energy PCE inflation. ${ }^{4}$ Beginning with the work of Stephen Cecchetti, Michael Bryan, and others in the 1990s (Bryan and Pike, 1991; Bryan and Cecchetti, 1994; and Bryan, Cecchetti, and Wiggins, 1997), core inflation measures based on robust estimators of the central tendencymedians and trimmed means-gained greater currency. The trimmed-mean PCE inflation rate produced by the Federal Reserve Bank of Dallas is a member of this family.

Core measures of this form do not exclude a priori any particular item or class of items, but rather exclude fixed proportions of mass from the lower and upper tails of the distribution of disaggregated price changes in each period of observation (typically a month). Notable examples for the United States, in addition to the Dallas Fed measure, include the weightedmedian CPI inflation rate and the 16 percent trimmed-mean CPI inflation rate published by the Federal Reserve Bank of Cleveland. Abroad, the Reserve Bank of Australia, Bank of Canada, and Reserve Bank of New Zealand all make reference to median or trimmed-mean measures of inflation in their official monetary policy statements; monetary policy statements of the Reserve Bank of Australia, in particular, refer to these measures as measures of underlying inflation. .5

Earlier studies have noted some advantages of trimmed-mean core inflation measures over exclusion-based measures. Brischetto and Richards (2006) examine data for Australia, the United States, Japan, and the euro area and find that trimmed-mean CPIs outperform headline and exclusion measures on a range of different criteria, including smoothness, ability to track movements in trend headline inflation, and predictive power for near-term headline inflation. Meyer and Venkatu (2014) focus specifically on forecasting ability and find that the median and 16 percent trimmed CPI inflation rates provide better out-of-sample forecasts of headline CPI inflation, over horizons of 6 to 36 months, than either headline CPI or CPI excluding food and energy. More recently, Ball and Mazumder (2019) compare ex-food-andenergy PCE inflation with weighted-median PCE inflation, which they find to be relatively less volatile and more strongly (and stably) linked with unemployment in Phillips curve regressions. $\underline{6}$

The intuitive argument for trimmed means over exclusion-based measures of core inflation typically notes that for standard exclusion sets-such as food and energy items-it is often the case that there are items outside the exclusion set that display price changes at least as volatile as those of the excluded items. Not all food and energy items are equally volatile, nor are all of the most volatile items exclusively food and energy. - This is also one argument, among several, that Bullard (2011) makes against the use of the ex-food-and-energy measure in monetary policymaking.

The more formal, statistical case for trimming draws on insights from robust statistics (Hogg, 1974, and Prescott and Hogg, 1977). If the distributions of monthly price changes are heavy tailed, then the sample mean is unlikely to be an efficient estimator of the distribution's location or central tendency. Compared with a normal distribution, for example, samples from heavy-tailed distributions are more likely to contain extreme realizations far from the distribution's central tendency. Since the sample mean is sensitive to these realizations-and since extreme realizations in one direction are, in any given month, unlikely to be matched exactly by extreme realizations in the other direction-the sample mean is apt to be a noisy 


\section{Dolmas and Koenig}

estimator of the distribution's location. Bryan, Cecchetti, and Wiggins (1997) make this argument formally and through Monte Carlo simulations in an analysis of inflation in the CPI and producer price index. Dolmas (2005) makes a similar argument in the case of PCE inflation and provides evidence of excess kurtosis in the distributions of monthly price changes in the PCE basket.

The underlying data for the trimmed-mean PCE are 178 disaggregated price and quantity series; in nominal spending terms, these disaggregated series add up to roughly 100 percent of total personal consumption expenditures. $\frac{8}{\text { The }}$ Tuantity data are necessary to aggregate the price changes. As described in Dolmas (2005), the form of the aggregation weights is derived from a linear approximation to chain aggregation; in practice, they are close to Tornqvist weights.

The particular disaggregation of PCE used in the construction of the trimmed mean is available consistently from January 1977; the trimmed-mean PCE inflation rate is thus available from February 1977. Monthly real-time vintages of the data, beginning in 2005, are available in the archival ALFRED ${ }^{\circledast}$ database of the Federal Reserve Bank of St. Louis. 9

The construction of the Dallas Fed trimmed-mean PCE inflation rate differs from other trimmed-mean inflation measures-such as the Cleveland Fed's trimmed-mean CPI-in a few important respects. Notably, the trimming proportions for the trimmed-mean PCE are asymmetric: Since 2009, its calculation trims out 24 percent of the mass (using expenditureshare weights) from the lower tail and 31 percent from the upper tail. $\underline{10}$ The trimming proportions were chosen to minimize the expected distance (in a root-mean-square sense) between the annualized monthly trimmed-mean inflation rate series and three proxies for unobserved "true" core inflation: a centered 36-month moving average of monthly all-items inflation following Bryan, Cecchetti, and Wiggins (1997), a forward-looking 24-month moving average, and a band-pass filtered trend that isolates movements in all-items inflation with a period below 36 months. $\underline{11}$

Another important difference, relative to CPI-based measures, is the potential for revision. The trimmed-mean PCE series is revised as the underlying data from the Bureau of Economic Analysis (BEA) are revised, with a rhythm typical to National Income and Produce Accounts (NIPA) releases-that is, minor revisions to the most recent month's data over the subsequent couple months and a major revision, extending back several years, annually (with the release of data for June). The parameters governing the construction of trimmed-mean PCE inflation have been revised once, following the 2009 comprehensive NIPA revision. $\underline{12}$

\section{EVALUATION}

\subsection{Bias}

For core inflation to usefully serve as an indicator of trend headline inflation in policy deliberations and Federal Reserve communications, it is important that it neither systematically overstate nor systematically understate headline inflation. When inflation data are subject to revision, what matters are systematic deviations of first-release core inflation from 


\section{Table 1}

\section{A. Mean Core PCE Inflation Compared with Mean Headline PCE Inflation}

\begin{tabular}{lcccc} 
& \multicolumn{2}{c}{ Mean core inflation } & \multicolumn{2}{c}{ Mean } \\
\cline { 2 - 3 } & Ex F\&E $^{\dagger}$ & Trimmed mean & Headline $^{\ddagger}$ \\
\hline 2005:Q2-2018:Q2 & 1.61 & 1.78 & 1.77 \\
\hline 1996:Q1-2018:Q2 & 1.60 & $1.90 \S \S$ & 1.81 \\
\hline
\end{tabular}

\section{B. Median Core Inflation Compared with Median Headline Inflation}

\begin{tabular}{lcccc} 
& \multicolumn{2}{c}{ Median core inflation } & & Median \\
\cline { 2 - 3 } & Ex F\&E $^{\dagger}$ & Trimmed mean & Headline $^{\ddagger}$ \\
\hline 2005:Q2-2018:Q2 & $1.52^{*}$ & $1.79^{\S}$ & 1.95 \\
\hline 1996:Q1-2018:Q2 & $1.60^{* *}$ & $1.95^{\S \S}$ & 1.96
\end{tabular}

NOTE: Ex F\&E, excluding fuel and energy. ${ }^{\dagger}$ Data are first release or as close as possible to first release. ${ }^{\ddagger}$ Data are September 11, 2018, vintage. */**Difference with headline PCE inflation is statistically significant at the 10/5 percent level. $\$ / \$ \S$ Difference with ex-food-and-energy PCE inflation is statistically significant at the 10/1 percent level. SOURCE: BEA, Federal Reserve Bank of St. Louis ALFRED ${ }^{\circledast}$ database, and authors' calculations.

\section{Figure 1}

\section{Trimmed-Mean and Headline PCE Inflation Share a Common Longer-Run Trend}

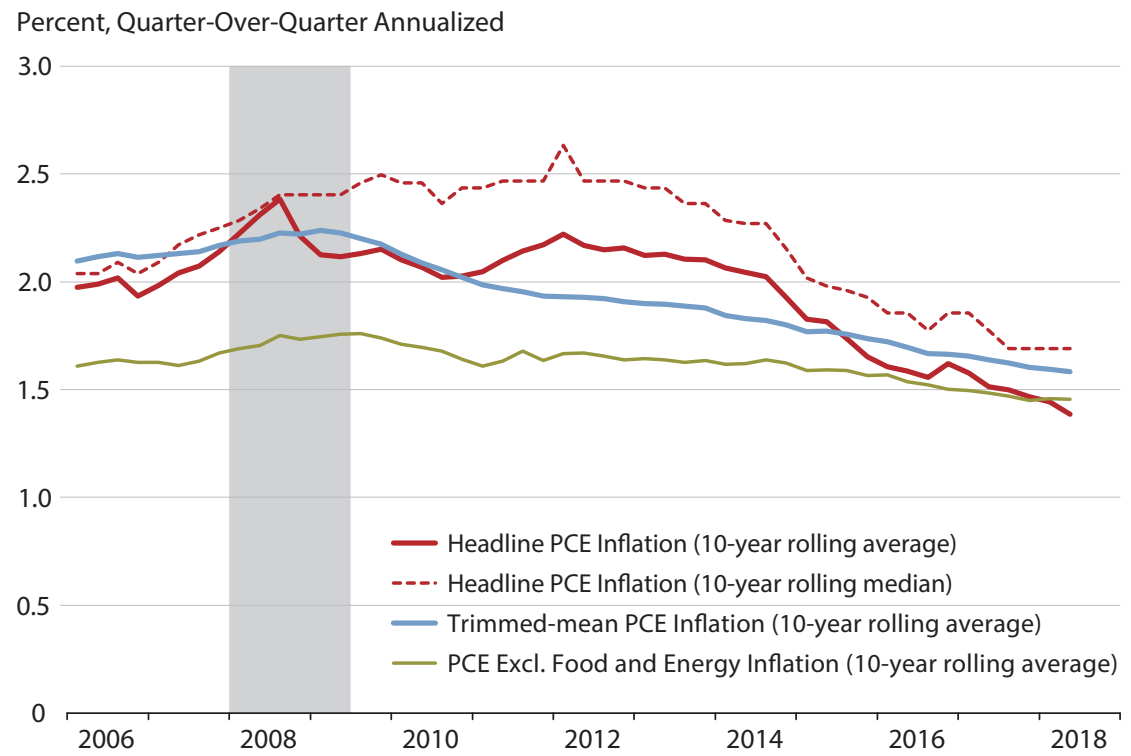

SOURCE: BEA, Federal Reserve Bank of St. Louis ALFRED ${ }^{\circledR}$ database, and authors' calculations. 


\section{Dolmas and Koenig}

latest-vintage headline inflation. It is, after all, first-release core inflation data that policymakers and the public will be watching and reacting to in real time, while it is the latest-vintage headline numbers that are relevant to an ex-post assessment of inflation-control performance. $\frac{13}{3}$ Data for real-time trimmed-mean PCE inflation start in 2005:Q2 and for real-time ex-foodand-energy PCE inflation start in 1996:Q1. Table 1A shows mean core and headline inflation rates over sample periods that begin on those dates, while Table $1 \mathrm{~B}$ shows the corresponding median core and headline inflation rates. (There is little difference between mean and median core inflation, but skew in headline inflation is significant at the 1 percent level.) Additionally, Figure 1 shows plots of rolling 10-year mean core inflation and rolling 10-year mean and median headline inflation. By averaging over long periods, the tables and the figure filter out high frequency and cyclical variation in inflation, highlighting longer-run trends.

The first main lesson from Table 1 and Figure 1 is that trimmed-mean inflation runs higher than ex-food-and-energy inflation: The choice between the two core inflation measures matters. Both the difference between the means of the two core inflation rates and the difference between their medians is highly statistically significant over the sample period that begins in 1996. In addition, the difference between median core inflation rates is significant at the 10 percent level over the sample period that begins in 2005 .

Given that trimmed-mean and ex-food-and-energy core inflation tell very different stories, which story is more accurate? The second main lesson from Table 1 is that trimmed-mean inflation has been the better real-time approximation to headline inflation: Ex-food-andenergy inflation is downwardly biased by 16 to 21 basis points, depending on the sample period, whereas trimmed-mean inflation has stayed within 10 basis points of headline inflation, on average. Similarly, median ex-food-and-energy inflation is 43 to 46 basis points below median headline inflation-a much larger shortfall than the 1- to 16-basis-point gap between median headline and median trimmed-mean inflation. While none of the mean inflation gaps is statistically significant at conventional levels, the shortfall in median ex-food-and-energy inflation is statistically significant at the 5 percent level over the sample beginning in 1996 and at the 10 percent level over the sample beginning in 2005. ${ }^{14}$ If you want a sense of whether trend headline inflation is at, above, or below the FOMC's 2 percent longer-run target, Table 1 suggests you should probably pay more attention to trimmed-mean inflation releases than to ex-food-and-energy inflation releases.

\subsection{Links to Slack}

Analysts and policymakers sometimes use inflation data to draw inferences about slack. For example, the Congressional Budget Office (CBO) historically has made revisions to its estimates of the natural rate of unemployment based on the behavior of inflation. The strength and robustness of the relationship between early-release estimates of an inflation measure and latest-vintage estimates of slack determines the usefulness of that inflation measure as a real-time indicator of resource utilization. $\frac{15}{15}$ Accordingly, we regress early-release estimates of inflation, detrended using the Survey of Professional Forecasters (SPF) measure of longrun inflation expectations, on a constant and latest-vintage $\mathrm{CBO}$ estimates of the unemploy- 


\section{Table 2}

Which Inflation Measure Is Most Closely, and Reliably, Related to Slack?

\begin{tabular}{|c|c|c|c|c|}
\hline & Inflation measure ${ }^{\dagger}$ & Constant (S.E.) & $U-U^{*}$ (S.E.) & Adj. $R^{2}$ \\
\hline \multirow[t]{3}{*}{ 2005:Q2-2018:Q2 } & Headline & $-0.146(0.316)$ & $-0.124(0.103)$ & 0.034 \\
\hline & Ex F\&E & $-0.241(0.070)$ & $-0.136(0.031)$ & 0.488 \\
\hline & Trimmed mean & $0.035(0.079)$ & $-0.197(0.039)$ & 0.651 \\
\hline \multirow[t]{3}{*}{ 1996:Q1-2018:Q2 } & Headline & $-0.367(0.170)$ & $-0.048(0.067)$ & -0.001 \\
\hline & Ex F\&E & $-0.531(0.073)$ & $-0.049(0.031)$ & 0.051 \\
\hline & Trimmed mean & $-0.120(0.065)$ & $-0.152(0.033)$ & 0.432 \\
\hline \multirow[t]{3}{*}{ 1981:Q4-2018:Q2 } & Headline & $-0.200(0.166)$ & $-0.052(0.075)$ & 0.000 \\
\hline & Ex F\&E & $-0.166(0.138)$ & $-0.074(0.061)$ & 0.023 \\
\hline & Trimmed mean & $-0.151(0.059)$ & $-0.203(0.040)$ & 0.458 \\
\hline
\end{tabular}

NOTE: 'Inflation measures used in the regressions are deviations of inflation rates from Survey of Professional Forecasters 10-year inflation expectations. S.E., standard error. Ex F\&E, excluding fuel and energy. First-release inflation data were used whenever possible; when these data were unavailable (before 2005:Q2 for trimmed-mean inflation and before 1996:Q1 for conventional core inflation) the earliest-available vintage was used instead. The unemployment gap is lagged four quarters, but results were qualitatively similar with a one-quarter lag. Standard errors are NeweyWest adjusted. Coefficients statistically significant at the 1 percent level are bolded.

SOURCE: BEA; BLS; CBO; Federal Reserve Bank of Philadelphia Survey of Professional Forecasters; Federal Reserve Bank of St. Louis ALFRED ${ }^{\circledR}$ database; authors' calculations.

\section{Figure 2}

\section{SPF-Detrended Headline PCE Inflation Is Only Loosely Related to Labor-Market Slack}

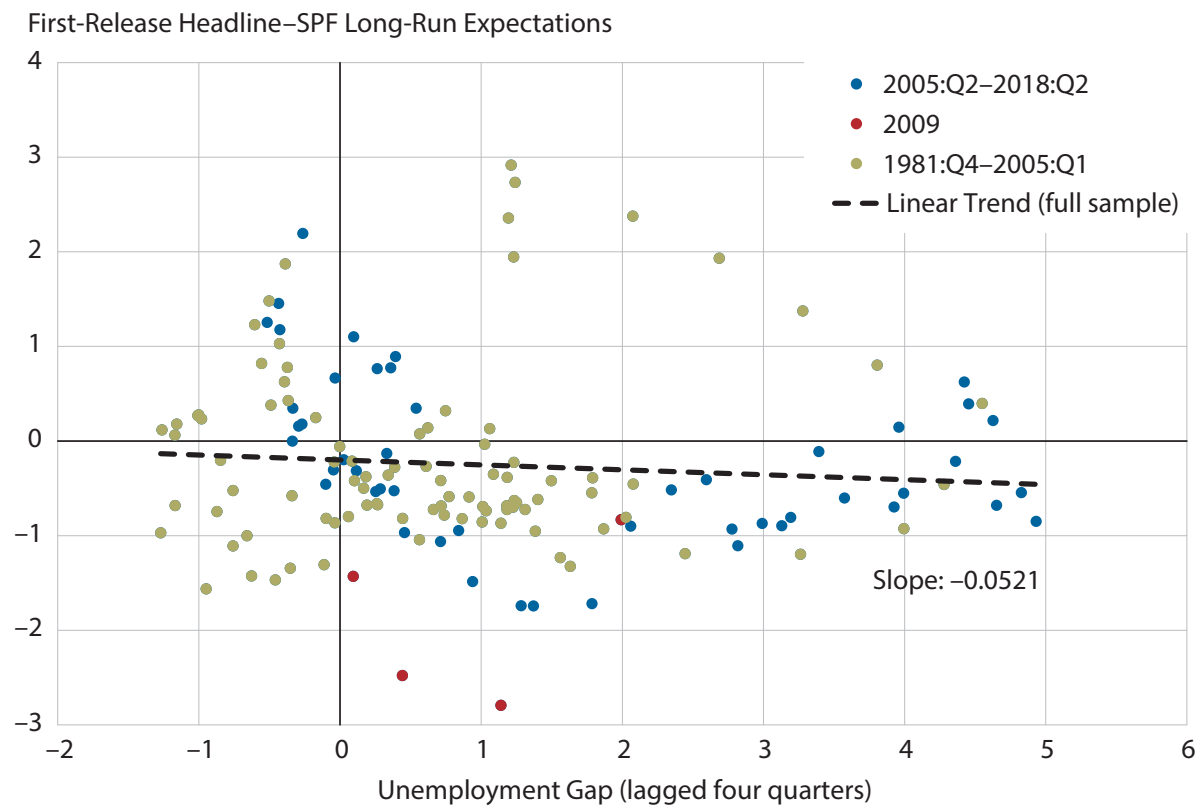

SOURCE: BEA; BLS; CBO; Federal Reserve Bank of Philadelphia Survey of Professional Forecasters; Federal Reserve Bank of St. Louis ALFRED ${ }^{\circledast}$ database; authors' calculations. 
Figure 3

\section{SPF-Detrended Ex-Food-and-Energy PCE Inflation Is Only Loosely Related to Labor- Market Slack}

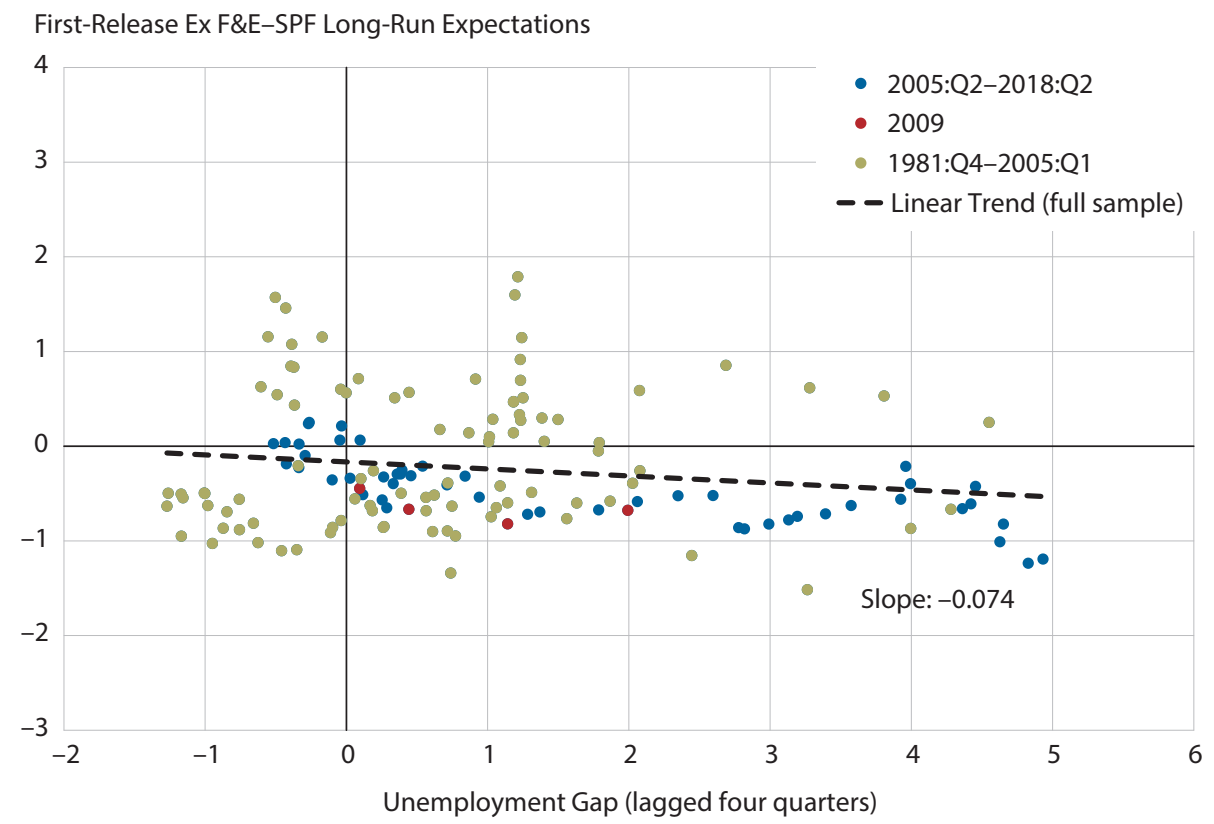

NOTE: Ex F\&E, excluding food and energy.

SOURCE: BEA; Bureau of Labor Statistics; CBO; Federal Reserve Bank of Philadelphia Survey of Professional Forecasters; Federal Reserve Bank of St. Louis ALFRED ${ }^{\circledR}$ database; and authors' calculations.

ment gap. The results-shown in Table 2 and Figures 2, 3, and 4-indicate that deviations of trimmed-mean inflation from long-run expected inflation are more strongly and more reliably related to labor-market slack than are similar deviations of headline inflation or ex-foodand-energy inflation. The coefficient on the unemployment gap is larger in magnitude in the trimmed-mean regressions than in either the ex-food-and-energy or headline regressions and is highly statistically significant. The constant term is smaller in magnitude than in the ex-food-and-energy or headline regressions and statistically significant in only one instance. There is no evidence that the relationship between trimmed-mean inflation and the unemployment gap has deteriorated over time. The relationship appears to have been robust even to the Financial Crisis (cf. Figure 4).

Recapping, deviations of trimmed-mean inflation from SPF long-run inflation expectations are a better indicator of whether slack remains in the labor market (as gauged, ex post, by the $\mathrm{CBO}$ ) than are deviations of either headline or ex-food-and-energy inflation. Put another way, trimmed-mean inflation is more successful at filtering out transitory inflation variation than is ex-food-and-energy inflation: The deviation of trimmed-mean inflation from trend (as captured by SPF long-run expectations) better approximates inflation's cyclical component. 


\section{Figure 4}

\section{SPF-Detrended Trimmed-Mean PCE Inflation Is Connected Fairly Strongly to Labor- Market Slack}

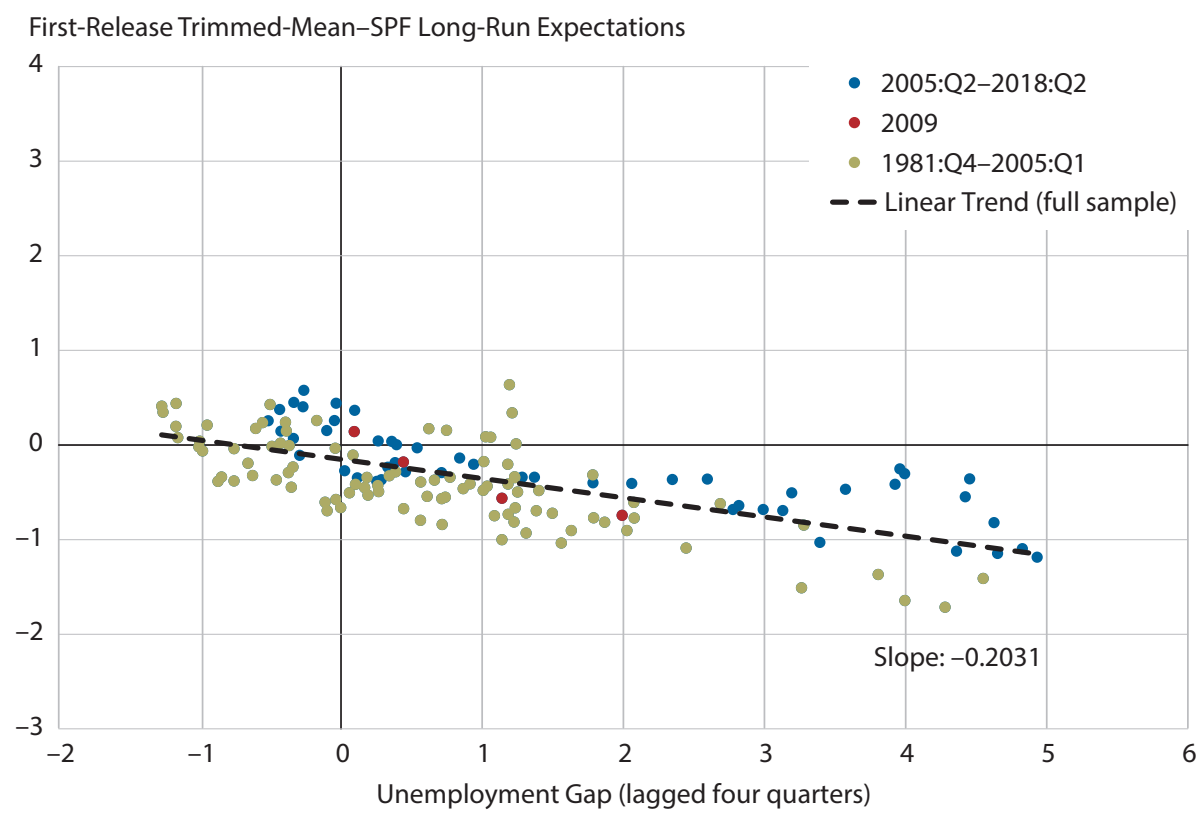

SOURCE: BEA; BLS; CBO; Federal Reserve Bank of Philadelphia Survey of Professional Forecasters; Federal Reserve Bank of St. Louis ALFRED ${ }^{\circledast}$ database; and authors' calculations.

\subsection{Forecasting Headline Inflation}

Which core inflation measure is most useful for predicting future headline inflation? Answering that question accurately requires careful thought about how best to go about estimating forecasting equations in real time. Koenig, Dolmas, and Piger (2003) show that if you will be forecasting using first-release data, then you should estimate your forecasting equation with first-release data on its right-hand side. Analysts often, instead, use end-of-samplevintage real-time data (the most up-to-date vintage available in real time) on the right-hand side of their real-time forecasting equations. For the left-hand-side variable, the obvious choice is end-of-sample data. However, there are potential gains in coefficient precision (hence, forecast accuracy) from stripping unforecastable noise from the left-hand-side variable before estimation. Gains will be most evident in smaller samples. When forecasting inflation, depending on the forecast horizon, stripping out unforecastable noise could mean using trimmedmean or ex-food-and-energy inflation as the dependent variable, even if it is headline inflation that you are ultimately interested in forecasting (Koenig and Atkinson, 2012). $\underline{16}$ To shed light on the potential usefulness of core inflation in real-time forecasting of headline inflation, we undertake two simple exercises. 
Table 3

\section{A. Rule-of-Thumb PCE Inflation Forecasting}

\begin{tabular}{lccc} 
& \multicolumn{3}{c}{ Root mean-square error } \\
\cline { 2 - 4 } Rule-of-thumb forecast & 2006:Q2-2018:Q2 & 1996:Q1-2018:Q2 & 1981:Q4-2018:Q2 \\
\hline Lagged headline & 1.472 & 1.229 & 1.411 \\
\hline Lagged ex. food and energy & 1.060 & 0.998 & 1.218 \\
\hline Lagged trimmed mean & 1.134 & 0.985 & 0.923
\end{tabular}

\section{B. Rule-of-Thumb PCE Inflation Forecasting (excluding 2009)}

\begin{tabular}{lccc} 
& \multicolumn{3}{c}{ Root mean-square error } \\
\cline { 2 - 4 } Rule-of-thumb forecast & 2006:Q2-2018:Q2 & 1996:Q1-2018:Q2 & 1981:Q4-2018:Q2 \\
\hline Lagged headline & 1.02 & 0.95 & 1.27 \\
\hline Lagged ex. food and energy & 0.82 & 0.87 & 1.16 \\
\hline Lagged trimmed mean & 0.84 & 0.81 & 0.81 \\
\hline
\end{tabular}

NOTE: When the first-release inflation series was unavailable (before 2005:Q2 for trimmed-mean inflation and before 1996:Q1 for conventional-core inflation), the earliest-available vintage was used instead.

SOURCE: BEA, Federal Reserve Bank of St. Louis ALFRED ${ }^{\circledR}$ database, and authors' calculations.

Rule-of-Thumb Forecasting. A simple rule of thumb is to set your forecast of inflation over the next four quarters equal to observed inflation over the most recent four-quarter period. The relevant "observed inflation" is first release, while the variable to be forecasted is latest-vintage headline inflation. Results are shown in Table 3A for three sample periods: (i) the period over which we have real-time trimmed-mean inflation, (ii) the period over which we have real-time ex-food-and-energy inflation, and (iii) an extended sample. In every case, lagged core inflation is a substantially better rule-of-thumb forecaster than is lagged headline inflation. Differences in forecast performance across the two core inflation measures are relatively small over those samples where real-time, first-release data are available.

Table 3A results may be distorted by the aftermath of the Financial Crisis, which brought about a sharp decline in inflation during 2009. Most analysts would not have relied on a rule-of-thumb inflation forecast during that period. As it turns out, though, excluding the immediate aftermath of the Financial Crisis from the analysis does not alter any of our main conclusions (Table 3B). It remains the case that rule-of-thumb forecasts based on lagged core inflation do notably better than those based on headline inflation and that differences in forecast performance across the two core inflation measures are relatively small over samples where real-time, first-release data are available.

Recursive Real-Time Forecasts of Headline Inflation. We also recursively estimate an inflation-forecasting equation of the form

$$
\pi(t)=\beta_{0}+\beta_{1} \pi(t-4)+\beta_{2} \pi^{c}(t-4)+\beta_{3} \pi^{e}(t-4)+\gamma u(t-4)+\varepsilon(t),
$$




\section{Table 4}

\section{A. Root Mean-Square Forecast Errors from Equation (1), 2006:Q2-2018:Q2 (excluding 2009)}

\begin{tabular}{lcc} 
& \multicolumn{1}{c}{ Estimated recursively over sample period starting... } \\
\cline { 2 - 3 } & $1996: \mathrm{Q} 1$ & $1982: \mathrm{Q} 4$ \\
\hline$\pi^{\mathrm{c}}=$ Ex. food and energy & 1.21 & 0.87 \\
\hline$\pi^{\mathrm{c}}=$ Trimmed mean & 1.12 & 0.89 \\
\hline
\end{tabular}

\section{B. Root Mean-Square Forecast Errors from Equation (1) with $\pi^{\mathrm{c}}$ Replacing $\pi$ on the Left-Hand Side, 2006:Q2-2018:Q2 (excluding 2009)}

\begin{tabular}{lcc} 
& \multicolumn{2}{c}{ Estimated recursively over sample period starting... } \\
\cline { 2 - 3 } & $1996: \mathrm{Q} 1$ & $1982: \mathrm{Q} 4$ \\
\hline$\pi^{\mathrm{c}}=$ Ex. food and energy & 0.87 & 0.89 \\
\hline$\pi^{\mathrm{c}}=$ Trimmed mean & 0.84 & 0.89
\end{tabular}

SOURCE: BEA; Federal Reserve Bank of Dallas; BLS; Federal Reserve Bank of Philadelphia Survey of Professional Forecasters; Federal Reserve Bank of St. Louis ALFRED ${ }^{\circledR}$ database; and authors' calculations.

where $u$ is the unemployment rate, $\pi$ is four-quarter headline inflation, $\pi^{c}$ is either ex-foodand-energy or trimmed-mean inflation, $\pi^{e}$ is SPF long-run inflation expectations, and $\varepsilon(t)$ is an error term. $\frac{17}{}$ End-of-sample vintage data are used on the equation's left-hand side and firstrelease data (or as close to first release as possible) are used on the right-hand side. The first forecast is for 2006:Q2, using first-release data for 2005:Q2. The final forecast is for 2018:Q2, using first-release data for 2017:Q2. We use two different sample starting points: 1996:Q1 and 1982:Q4. The real-time forecasts are compared with latest-vintage headline PCE inflation. The four-quarter period immediately following the Financial Crisis (2009:Q1-2009:Q4) is excluded from both the estimation and forecast evaluation. As shown in Table 4A, forecast performance is slightly better using the trimmed-mean measure of core inflation when the sample period used for estimation is short. That advantage disappears (and forecast performance improves) when the sample period is extended back to the 1980s.

As previously noted, more-precise coefficient estimates (and, so, better forecasts) can sometimes be obtained by stripping noise from the dependent variable, suggesting that there might be an advantage to replacing $\pi(t)$ on the left-hand side of equation (1) with $\pi^{c}(t)$. Again, left-hand-side data are end-of-sample vintage, and forecasts are compared with latest-vintage headline PCE inflation data. Results are displayed in Table 4B.

Forecasting performance with a short sample is much improved when core inflation is used as the left-hand-side variable during estimation, regardless of which core inflation measure is used. (Compare the first columns of Tables 4A and 4B.) However, there is no improvement when the estimation period is extended back to the 1980s. (Compare the second columns of Tables 4A and 4B.) Independent of the sample start date, ex-food-and-energy and trimmed- 


\section{Dolmas and Koenig}

mean core inflation measures are about equally useful for forecasting headline inflation. Interestingly, the root-mean-square forecast errors reported in Table $4 \mathrm{~B}$ are no better than those obtained from simple rule-of-thumb forecasting based on lagged core inflation. (Compare the root-mean-square errors reported in Table 4B with the left-column entries in Table 3B.)

At a four-quarter horizon, evidently, real-time forecasts of core inflation usefully serve, also, as forecasts of headline inflation. It makes little difference whether the core measure is ex-food-and-energy inflation or trimmed-mean inflation.

\section{SUMMARY AND CONCLUSIONS}

Trimmed-mean PCE inflation is more strongly and reliably related to labor-market slack than are either headline PCE inflation or ex-food-and-energy PCE inflation, and it is more predictable than either of these alternative inflation measures. Real-time trimmed-mean inflation forecasts also serve well as forecasts of headline inflation, sometimes outperforming models that try to forecast headline inflation directly. First-release trimmed-mean inflation rates, averaged over samples that span the business cycle, match up well with latest-vintage mean and median headline inflation rates calculated over the same samples.

We conclude that trimmed-mean inflation shares a long-run trend with headline inflation, but filters out the short-term variation in headline inflation that obscures the relationship between headline inflation and labor-market slack. These features make trimmed-mean inflation useful for forecasting headline inflation, drawing inferences about slack, and explaining Federal Reserve policy decisions.

Ex-food-and-energy PCE inflation appears to be less successful than trimmed-mean PCE inflation at filtering the short-term, noncyclical elements from headline PCE inflation and has substantially understated headline inflation over sample periods that span the business cycle. Consequently, it is less informative about headline inflation trends and about slack and less useful as a communications tool. However, over sample periods that include the recent downturn and ongoing expansion, ex-food-and-energy inflation has been every bit as useful a forecasting tool as trimmed-mean inflation. 


\section{NOTES}

1 See Aoki (2001).

2 An alternative solution to the delayed-impact issue is to have policy respond to forecasted headline inflation. As we've just discussed, however, superior forecasts of headline inflation may come from a model of core inflation.

$\underline{3}$ The trimmed-mean inflation rate, discussed in more detail later in the article, is constructed by excluding, or "trimming," the most extreme component price changes each month. Which components get trimmed thus varies from month to month, and no particular component - whether food, energy, or otherwise-is necessarily included or excluded.

4 The earliest reference to an exclusion-based measure of inflation that we know of is to CPI excluding food, which appeared in the Bureau of Labor Statistics (BLS) detailed CPI reports in 1957 and was subsequently referenced in The Economic Report of the President in 1958. See the 1957 CPI reports archived in FRASER ${ }^{\circledast}$ of the Federal Reserve Bank of St. Louis: https://fraser.stlouisfed.org/title/58.

5 See recent monetary policy statements by these central banks: Reserve Bank of New Zealand (2018), Reserve Bank of Australia (2018), and Bank of Canada (2018).

6 Importantly, the Ball-Mazumder analysis is limited to latest-vintage data, whereas we use real-time vintage data to the extent possible.

$\underline{7}$ For example, in data from 1993 to the present, more-processed food items, such as cereals, bakery products, and alcoholic beverages, all have standard deviations of their monthly price changes that are less than the median standard deviation across nonfood, nonenergy components. Electricity services, the least volatile energy component, has a standard deviation only slightly above the nonfood, nonenergy median. And conversely, 44 nonfood, nonenergy items have standard deviations above the median standard deviation among food and energy items.

8 The sources of these data are the Bureau of Economic Analysis's (BEA's) Underlying Detail Tables 2.4.4U and 2.4.5U. Note that because their potential sign changes confound the cumulation of expenditure weights, net foreign travel and net expenditures abroad are excluded from the calculation of the trimmed mean. The weight of these two categories has averaged -0.15 percent over the period for which the trimmed mean is calculated.

9 See https://alfred.stlouisfed.org/release?rid=323.

10 From its introduction in 2005 to the BEA's comprehensive revision of the National Income and Product Accounts (NIPA) in 2009, the lower and upper trimming proportions had been 19.4 percent and 25.4 percent, respectively.

11 This pass band was chosen to maximize the correlation between the resulting trend estimate and the effective federal funds rate. As discussed in Dolmas (2005), the rationale for this third proxy is to treat true core inflation as the inflation to which policymakers seem to have responded.

12 As part of the 2009 revision, the BEA reorganized its underlying data on component-level PCE prices and quantities, combining some series, disaggregating others and, importantly, separating out the activity of the nonprofit sector from that of the household sector.

13 Except as noted, results were unchanged when we compared first-release core inflation with headline inflation as it appeared after one annual revision.

14 The latter result is not robust to a comparison of first-release ex-food-and-energy inflation with first-annual-revision headline inflation.

15 Alternatively, the analyst armed with a real-time slack measure in which she has confidence might hope to use the behavior of inflation to draw inferences about longer-run inflation expectations. Then it will be useful for early releases of the inflation measure to be strongly and robustly related to longer-run expectations, without having to control for a wide range of influences other than slack.

16 Depending on the data-revision process, it might also mean using early-release data on the left-hand side of the forecasting equation. See, again, Koenig, Dolmas, and Piger (2003).

17 The rule-of-thumb forecasting model is the special case of equation (1) where either $\beta_{1}=1$ and all other coefficients are restricted to equal zero or $\beta_{2}=1$ and all other coefficients are restricted to equal zero. Equation (1) can be thought of as the reduced form of a three-equation system in trend inflation, cyclical inflation, and transitory 


\section{Dolmas and Koenig}

inflation: $\pi^{e}(t)=\left(1-\delta_{1}-\delta_{2}-\delta_{3}\right) \pi^{*}+\delta_{1} \pi^{e}(t-4)+\delta_{2} \pi(t-4)+\delta_{3} \pi^{c}(t-4)+\varepsilon_{1}(t) ; \pi^{c}(t)-\pi^{e}(t)=a_{1}\left[\pi^{c}(t-4)-\pi^{e}(t-4)\right]+$ $a_{2}\left[\pi(t-4)-\pi^{e}(t-4)\right]+\gamma\left[u(t-4)-u^{*}\right]+\varepsilon_{2}(t) ;$ and $\pi(t)-\pi^{c}(t)=\rho\left[\pi(t-4)-\pi^{c}(t-4)\right]+\varepsilon_{3}(t)$. Here, $\pi^{*}$ and $u^{*}$ are constants and $\varepsilon_{1}, \varepsilon_{2}$, and $\varepsilon_{3}$ are error terms.

\section{REFERENCES}

Aoki, Kosuke. "Optimal Monetary Policy Responses to Relative-Price Changes." Journal of Monetary Economics, 2001, 48(1), pp. 55-80; https://doi.org/10.1016/s0304-3932(01)00069-1.

Ball, Laurence and Mazumder, Sandeep. "The Nonpuzzling Behavior of Median Inflation." NBER Working Paper 25512, National Bureau of Economic Research, January 2019; https://doi.org/10.3386/w25512.

Bank of Canada. Monetary Policy Report. January 2018; https://www.bankofcanada.ca/wp-content/uploads/2018/01/mpr-2018-01-17.pdf.

Brischetto, Andrea and Richards, Anthony. "The Performance of Trimmed Mean Measures of Inflation." Discussion Paper No. 2006-10, Reserve Bank of Australia Research, 2006; https://doi.org/10.2139/ssrn.950209.

Bryan, Michael and Cecchetti, Stephen. "Measuring Core Inflation," in N. Gregory Mankiw, ed., Monetary Policy. Chicago: University of Chicago Press, 1994, pp. 195-215; https://doi.org/10.3386/w4303.

Bryan, Michael; Cecchetti, Stephen and Wiggins, Rodney. "Efficient Inflation Estimation." NBER Working Paper 6183, National Bureau of Economic Research, 1997; https://doi.org/10.3386/w6183.

Bryan, Michael and Pike, Christopher. "Median Price Changes: An Alternative Approach to Measuring Current Monetary Inflation." Federal Reserve Bank of Cleveland Economic Commentary, December 1991; https://fraser.stlouisfed.org/title/4515/item/495480\#scribd-open.

Bullard, James. "Measuring Inflation: The Core Is Rotten." Federal Reserve Bank of St. Louis Review. July/August 2011, 93(4), pp. 223-33; https://doi.org/10.20955/r.93.223-234.

Dolmas, Jim. "Trimmed Mean PCE Inflation." Working Paper No. 0506, Federal Reserve Bank of Dallas, July 2005; https://www.dallasfed.org/research/ /media/documents/research/papers/2005/wp0506.pdf.

Hogg, Robert. "Adaptive Robust Procedures: A Partial Review and Some Suggestions for Future Applications and Theory." Journal of the American Statistical Association, December 1974, 69(348), pp. 909-23; https://doi.org/10.2307/2286160.

Koenig, Evan F. and Atkinson, Tyler. "Inflation, Slack and Fed Credibility." Staff Papers No. 16, Federal Reserve Bank of Dallas, January 2012; https://www.dallasfed.org/ /media/documents/research/staff/staff1201.pdf.

Koenig, Evan F.; Dolmas, Sheila and Piger, Jeremy. "The Use and Abuse of Real-Time Data in Economic Forecasting." Review of Economics and Statistics, 2003, 85(3), pp. 618-28; https://doi.org/10.1162/003465303322369768.

Meyer, Brent and Venkatu, Guhan. "Trimmed-Mean Inflation Statistics: Just Hit the One in the Middle." Working Paper No. 12-17R, Federal Reserve Bank of Cleveland, 2014; https://doi.org/10.2139/ssrn.2580290.

Prescott, Philip and Hogg, Robert. "Trimmed and Outer Means and Their Variances." American Statistician, 1977, 31(4), pp. 156-57; https://doi.org/10.2307/2683537.

Reserve Bank of Australia. Statement on Monetary Policy. February 2018; https://www.rba.gov.au/publications/smp/2018/feb/pdf/statement-on-monetary-policy-2018-02.pdf.

Reserve Bank of New Zealand. Monetary Policy Report. February 2018; https://www.rbnz.govt.nz/-/media/ReserveBank/Files/Publications/Monetary\%20policy\%20statements/2018/ mpsfeb18.pdf. 